\title{
Self-perception of health and social determinants in high school adolescents
}

Stela Maris Aguiar Lemos ${ }^{(1)}$

Poliana Cristina Rocha(2)

Angel Martínez-Hernaéz ${ }^{(3)}$

(1) Universidade Federal de Minas Gerais UFMG, Belo Horizonte, Minas Gerais, Brasil.

(2) Universidade Federal de Minas Gerais UFMG, Prefeitura Municipal de Belo Horizonte (PBH), Belo Horizonte, Minas Gerais, Brasil.

(3) Universitat Rovira i Virgili; Medical Anthropology Research Center, Tarragona, Província de Tarragona, Espanha.

Research support source: The present study was carried out with the support of the Coordination for the Improvement of Higher Education Personnel (CAPES), Brazil. Process number: BEX 7377/14-2.

Conflict of interests: Nonexistent

\section{(c) (i)}

Received on: January 2, 2018 Accepted on: August 30, 2018

Corresponding address: Stela Maris Aguiar Lemos

Avenida Alfredo Balena, $n^{0} 190$, Sala 251 CEP: 30130-100 - Belo Horizonte, Minas Gerais, Brasil

E-mail: lemos.stela@gmail.com

\section{ABSTRACT}

Purpose: to verify the association between self-perception of health, gender, age, economic status, quality of life, cultural aspects and contexts of violence in high school adolescents.

Methods: an observational analytical cross-sectional study with a probabilistic sample composed of 386 high school students aged 15-19 years. The data collection was made in 16 public schools. Descriptive, bivariate and multivariate data analyses were made. Models with hierarchical entry of the blocks according to the level of determination established in the theoretical model were built, and for the evaluation of associations in the logistic regression models, the significance level of $5 \%$ was considered. The Odds Ratio and its respective confidence interval of $95 \%$ were used as a measure of the magnitude of the associations.

Results: the data revealed that more than two-thirds of the participants reported a positive self-perception of health and, in the hierarchical multiple logistic regression model, to have own house, to practice any religion, and the quality of life remained associated with positive Self-perception of health.

Conclusion: having their own house, practicing a given religion and having a better quality of life increased the chances of a positive self-perception of health.

Keywords: Adolescent; Adolescent Health; Self-Assessment; Social Determinants of Health 


\section{INTRODUCTION}

The analysis of health self-assessment has been increasingly accepted for constructing indicators that transcend morbidity and mortality rates for application in scientific research and in the construction of health actions.

One of such indicators is the "self-perception of health" or "self-perception of health status", based on subjective and objective criteria, being influenced by factors such as gender, age, social class, among others ${ }^{1}$. It is an efficient way of understanding individuals' perspective on their health and is also a good predictor of individual mortality and morbidity, including aspects of physical, emotional and cognitive health ${ }^{1-3}$. Currently, the investigation of the determinants and factors associated with the health and illness process began to value the perception of children and adolescents about their state of health ${ }^{2,4,5}$.

Although self-perception of health is considered an indicator of subjective well-being ${ }^{6}$, it has been shown to be feasible, reliable and it can be used in the construction of functional indicators ${ }^{7,8}$, to estimate the use of the health system ${ }^{9}$ and to understand the articulation between social and health context ${ }^{10}$. It is noteworthy that the literature points to the life cycle of adolescence as an important period in whichthe issue merits research, since it is a time of relevant changes and consolidation of individual and social identities that will reflect in the way of caring for their own health ${ }^{6,11}$.

The investigation of the self-perception of health arises from the theories of investigation of the selfconcept that has been pointed out as fundamental for the understanding of psychological, social, clinical and educational aspects ${ }^{6,12}$. Self-concept is considered to be a measure of personal satisfaction, the result of a set of partial perceptions about oneself, organized in a multidimensional way and in a hierarchical structure, composed by academic, social, personal and physical self-concepts ${ }^{12}$.

Thus, it is possible to consider that the study of self-concept in adolescents and their associations with social aspects can contribute to the understanding not only of self-care, but also to the elaboration of health promotion strategies, or for coping and preventive actions in this cycle of life.

Thus, the objective of the present study was to verify the association between self-perception in health with demographic, cultural and social determinants, context of violence and self-perception of quality of life of adolescents in high school.

\section{METHODS}

This is across-sectional observational study using a probabilistic sample composed of 384 high school students from public schools in Belo Horizonte, Minas Gerais. The study was approved by the Ethics Committee of the Federal University of Minas Gerais under CAAE: 14897013.4.0000.5149.

The research was carried out in 16 schools of the nine administrative regions of the city of Belo Horizonte. In an initial step, one school was drawn from each region and others were included as necessary for the final composition of the sample of adolescents. In this way, all the administrative regions of Belo Horizonte were represented in the study and, therefore, the aspects referring to the different territories were weighted.

The sample calculation was defined considering the absence of expected percentage estimates for the variables of interest. Thus, it was assumed that this percentage was $50 \%$, a value that maximizes the sample size. It was also considered a 95\% confidence level and a $5 \%$ margin of error. Considering those criteria as well as the number of eligible students enrolled in high school, the final sample was estimated in 384 adolescents

The study included students aged between 15 and 19 who agreed to participate signing the free and informed consent form by themselves, and another term signed by those responsible for adolescents up to the age of 17, 11 months and 29 days. Adolescents aged 18 and 19 signed just their own Informed Consent Term.

\section{Procedures}

Five research instruments were used: evaluation of self-perception of health, questionnaire for characterization of adolescents, Pediatric Questionnaire on Quality of Life - PedsQL Version 4.0, self-perception of the context of violence.

For the evaluation of self-perception of health, the question "How do you evaluate your health?" Was presented as a possible answer on a Likert scale with the options: very bad, bad, regular, good and excellent.

The instrument for characteristics of the adolescent participants consisted of a self-administered questionnaire, composed of closed questions in order to get a picture of the socioeconomic, cultural and demographic profile of the sample. This instrument consisted in the identification of age, sex, school year 
and socio-economic cultural profile, housing situation, TV watching habits, theater and cinema attendance, work, practice of religion and the Brazil Economic Classification Criteria (CCEB) ${ }^{13}$.

To evaluate the quality of life, the study used the Pediatric Questionnaire on Quality of Life - PedsQL, version $4.0^{14,15}$, a multidimensional instrument to evaluate the quality of life of children and adolescents. The final score of the instrument was obtained by triangulating the results of four axes, namely: physical, emotional, social and school mastery, totaling 23 questions. Thus, data analysis followed the authors' recommendation ${ }^{14,15}$.

The evaluation of the self-perception of violence was made using three questions with a 'yes' and 'no' answer, namely: "Have you ever committed any act of violence?"; "Have you ever suffered any violence?" And "Does violence impact your health?"

\section{Data analysis}

The variable response selected for the study was the result of the question

"How do you evaluate your health?" using the "very bad", "bad", "regular", "good" and "excellent" response options that were later categorized as "bad" (grouping of the answers "bad", "very bad" and "regular") and "good" (grouping of variables "good" and "excellent"). For analysis purposes, the following variables were defined as explanatory variables: sociodemographic characteristics, cultural aspects, violence context, quality of life through the PedsQL and health perception, which were distributed in a hierarchical model that consisted of four blocks, described as follows:

First Block - Sociodemographic characteristics: sex, age, school year, living situation (with whom they live), housing (own/leased), health insurance, economic classification and work.

- Second Block - Cultural aspects: time watching television, reading newspapers / magazines, attending museums, attending theater/cinema, practicing a religion.

- Third Block - Context of violence: you have already committed any of these acts; already suffered some of these acts and violence has an impact on your health.

- Fourth Block - Classification of quality of life: physical domain, emotional domain, social domain, school domain and total score
Descriptive analyses of all the variables of the study were carried out by means of absolute and relative frequency distribution of the categorical variables and numerical synthesis of the continuous variables. The results of the descriptive analysis were organized in tables and graphs according to the blocks of analysis as proposed in the theoretical model.

To analyze the association of categorical variables, the study used a Pearson's Chi-square test. In the case of continuous variables, the non-parametric Mann Whitney test was used, since the continuous variables: age, total score of the PedsQL, and health literacy score, all have asymmetric distribution (KolmogorovSmirnov test, $p>0.005$ ).

The tables with the bivariate analyzes were organized according to the blocks proposed in the hierarchical model. In this step, we considered the associations that werefound statistically significant at the level of $20 \%$ in order to be entered as variables in the multivariate model. We constructed models with hierarchical input of the blocks according to the level of determination established in the theoretical model. The variables with a statistically significant association to the level of $20 \%(p<0,20)$ in the bivariate analysis were considered in the multiple logistic regression models.

For the evaluation of the associations in the logistic regression models, the significance level of $5 \%$ was considered.In this way, associations with statistical significance were considered as statistically significant associations value-p $\leq 0,05$. As a measure of magnitude of the associations, the analysis usedOdds Ratioand their respective 95\% confidence interval. The adequacy of the models was evaluated by the test of Hosmer and Lemeshow.

The analysis was conducted in the hierarchical modeling as follows: 1) adjusting the model to the first block hierarchical level 1;2) Variables with statistical significance at $p=0.05$ in Block 1 setting were maintained in the block model $2 ; 3$ ) the variables with statistical significance $p \leq 0.05$ in blocks 1 and 2 were maintained in the model adjustment of block 3 , and so on until the adjustment of the last block. At the end of the procedure, the final model was obtained. When in a given block there was no variable associated with the event under analysis, this block was eliminated from the final model.

For all analyses, we used the program Statistical Package for the Social Sciences SPSS, version 21.0. 


\section{RESULTS}

Out of the 384 adolescents that participated, $70.3 \%$ were females. It was found that $24.7 \%$ of the students were in the first year, $19.3 \%$ in the second year and $56 \%$ in the third year. The average age of participants was 17.1 years, ranging from 15 to 19 years and $99.2 \%$ declared single marital status, while $55.3 \%$ stated they had health insurance. The majority, $90.9 \%$ lived with parents and siblings or only with parents.In the sample $51.3 \%$ of the adolescents declared to work or have already worked. The distribution of the adolescents according to economic class was: A1 - 0.3\%; A2 $5.2 \%$, B1 - 20.1\%; B2 - 32.6\%; C1 - 33.9\%; C2 - 7.0\% and $\mathrm{D}-1.0 \%$.

Of the 384 participants, 378 filled out the questionnaire of health self-perception. Of those who completed the form, $71.4 \%$ were female. The distribution of the students by grade level was: $25.1 \%$ for the first year, $19.6 \%$ for the second year and $55.3 \%$ for the third year (Table 1).

Table 1. Bivariate analysis of the association between health self-perception and socio-demographic characteristics*

\begin{tabular}{|c|c|c|c|}
\hline \multirow{2}{*}{ Characteristics } & \multicolumn{2}{|c|}{ Self-perception of Health } & \multirow{2}{*}{ Value-p** } \\
\hline & Bad & Good & \\
\hline \multicolumn{4}{|c|}{ Sex } \\
\hline Males & $18(22.5)$ & $91(30.5)$ & \\
\hline Females & $62(77.5)$ & $208(69.5)$ & 0.159 \\
\hline Total & $80(100.0)$ & $298(100.0)$ & \\
\hline \multicolumn{4}{|c|}{ School year } \\
\hline 1st Grade & $22(27.5)$ & $73(24.5)$ & \multirow{4}{*}{0.828} \\
\hline 2nd Grade & $16(20.0)$ & $58(19.5)$ & \\
\hline 3rd Grade & $42(52.5)$ & $167(56.0)$ & \\
\hline Total & $80(100.0)$ & $298(100.0)$ & \\
\hline \multicolumn{4}{|c|}{ Lives with } \\
\hline Parents and siblings & $69(87.3)$ & $274(92.3)$ & \\
\hline Others & $10(12.7)$ & $23(7.7)$ & 0.170 \\
\hline Total & $79(100.0)$ & $297(100.0)$ & \\
\hline \multicolumn{4}{|c|}{ Household } \\
\hline Home-ownership & $55(68.8)$ & $242(82.0)$ & \\
\hline Rented home & $25(31.3)$ & $53(18.0)$ & 0.009 \\
\hline Total & $80(100.0)$ & $295(100.0)$ & \\
\hline \multicolumn{4}{|c|}{ CCEB } \\
\hline Class A & $5(6.3)$ & $16(5.4)$ & \multirow{4}{*}{0.950} \\
\hline Class B & $41(51.3)$ & $156(52.3)$ & \\
\hline Class C e D & $34(42.5)$ & $126(42.3)$ & \\
\hline Total & $80(100.0)$ & $298(100.0)$ & \\
\hline \multicolumn{4}{|c|}{ Health Care } \\
\hline Yes & $34(45.9)$ & $158(57.2)$ & \\
\hline No & $40(54.1)$ & $118(42.8)$ & 0.083 \\
\hline Total & $74(100.0)$ & $276(100.0)$ & \\
\hline \multicolumn{4}{|c|}{ Currently works or has worked before } \\
\hline Yes & $44(55.0)$ & $150(50.3)$ & \\
\hline No & $36(45.0)$ & $148(49.7)$ & 0.459 \\
\hline Total & $80(100)$ & $298(100)$ & \\
\hline
\end{tabular}

* The number of information varies due to missing data ** Pearson's chi-square

Subtitle: CCEB $=$ Economic Classification Criteria Brazil 
Among variables in Block one, the variables "sex", "with whom they live" and "health insurance" were associated with "self-perception of health" at the level of $20 \%$ and were considered for the multiple logistic regression model (Table 1).
In Block 2, only the variable "attending museums" was associated with "self-perception of health" at the $20 \%$ level, being considered in the multivariate model (Table 2).

Table 2. Bivariate analysis of the association between self-perception of health and cultural aspects*

\begin{tabular}{|c|c|c|c|}
\hline \multirow{2}{*}{ Characteristics } & \multicolumn{2}{|c|}{ Self-perception of Health } & \multirow{2}{*}{ Value- $p^{* *}$} \\
\hline & Bad & Good & \\
\hline \multicolumn{4}{|c|}{ TV watching time } \\
\hline Less than 2 hours & $37(53.6)$ & $153(53.9)$ & \\
\hline More than 2 hours & $32(46.4)$ & $131(46.1)$ & 0.970 \\
\hline Total & $69(100)$ & $284(100.0)$ & \\
\hline \multicolumn{4}{|c|}{ Reads newspapers and magazines } \\
\hline Yes & $52(65.0)$ & $171(58.2)$ & \\
\hline No & $28(35.0)$ & $123(41.8)$ & 0.269 \\
\hline Total & $80(100.0)$ & $294(100.0)$ & \\
\hline \multicolumn{4}{|c|}{ Goes to museums } \\
\hline Yes & $25(31.3)$ & $64(21.6)$ & \\
\hline No & $55(68.8)$ & $232(78.4)$ & 0.072 \\
\hline Total & $80(100.0)$ & $296(100.0)$ & \\
\hline \multicolumn{4}{|c|}{ Goes to the theater/cinema } \\
\hline Yes & $69(86.3)$ & $262(88.2)$ & \\
\hline No & $11(13.8)$ & $35(11.8)$ & 0.634 \\
\hline Total & $80(100.0)$ & $297(100.0)$ & \\
\hline \multicolumn{4}{|c|}{ Practices a Religion } \\
\hline Yes & $54(68.4)$ & $240(81.4)$ & \\
\hline No & $25(31.6)$ & $55(18.6)$ & 0.012 \\
\hline Total & $79(100.0)$ & $295(100.0)$ & \\
\hline
\end{tabular}

* The number of information varies due to missing data ** Pearson's chi-square

In Block 3, only the variable "Have you ever suffered any act of violence?" Was associated with "self-perception of health" at the level of $20 \%$, being considered in the multivariate model (Table 3).

When analyzing the quality of life according to the self-perception of health, it was observed that the total PedsQL score presented medians of 67.4 (bad self-perception) and 77.2 (good self-perception); and averages of 67.0 with a standard deviation of 1.4 (bad self-perception) and 76.0 with a standard deviation of 0.6 (good self-perception). In the bivariate analysis, the Mann-Whitney test indicated $p$-value $<0.001$. Thus, Block four variable: "Quality of life - total PedsQL score" was associated with "self-perception of health" at a significance level of $20 \%$ and was used in the logistic regression model.
In the final model showed in Table 4, the following variables remained associated with good health selfevaluation: owning a home $(\mathrm{OR}=2.16 ; \mathrm{p}=0.014)$; not going to museums $(\mathrm{OR}=2.20 ; p=0.013)$; practicing a religion $(O R=1.91 ; p=0.043)$; and total quality of life score $(O R=1,08 ; p<0,001)$. Thus, having a home of their own, not going to museums and practicing a religion, increased by $2.16 ; 2.20 ; 2.11$ times, respectively, the chance of having good health self-perception. The increase in one point in the total quality of life score increased by $8.0 \%$ the chance of the adolescents to have a good health self-perception. The adequacy of the model - Hosmer and Lemeshow test - was considered good $(p=0.512)$. 
Table 3. Bivariate analysis of the association between self-perception of health and context of violence*

\begin{tabular}{cccc}
\hline \multirow{2}{*}{ Características } & \multicolumn{2}{c}{ Self-perception of Health } & \multirow{2}{*}{ Value-p** } \\
\cline { 2 - 2 } & \multicolumn{2}{c}{ Gad } & Has committed acts of violence \\
Yes & $52(65.8)$ & $179(61.1)$ & \\
No & $27(34.2)$ & $114(38.9)$ & 0.442 \\
Total & $79(100.0)$ & $293(100.0)$ & \\
Yes & \multicolumn{4}{c}{ Has suffered acts of violence } \\
No & $64(81.0)$ & $206(70.3)$ & 0.058 \\
Total & $15(19.0)$ & $87(29.7)$ & \\
Yes & $79(100)$ & $293(100.0)$ & \\
No & \multicolumn{2}{c}{ Violence affects health } \\
Total & $69(87.3)$ & $250(85.3)$ & 0.649 \\
\hline
\end{tabular}

* The number of information varies due to missing data** Pearson's chi-square

Table 4. Results of hierarchical multiple logistic regression analysis - Factors associated with positive self-perceived health

\begin{tabular}{|c|c|c|c|}
\hline Model & Adjusted OR & CI 95\% & Value-p \\
\hline \multicolumn{4}{|c|}{ Model 1 - Socio-demographic characteristics } \\
\hline Sex & 1.28 & $0.669-2.337$ & 0.425 \\
\hline Lives with parents & 1.39 & $0.600-3.234$ & 0.440 \\
\hline Home ownership & 1.97 & $1.094-3.535$ & 0.024 \\
\hline Health Insurance & 1.39 & $0.814-2.357$ & 0.230 \\
\hline \multicolumn{4}{|c|}{ Model 2 - Cultural aspects* } \\
\hline Does not go to museums & 1.94 & $1.100-3.432$ & 0.022 \\
\hline Practices a religion & 2.11 & $1.191-3.735$ & 0.001 \\
\hline \multicolumn{4}{|c|}{ Model 3 - Violence context** } \\
\hline Acts of violence not experienced & 1.81 & $0.949-3.469$ & 0.072 \\
\hline \multicolumn{4}{|c|}{ Model 4 - Quality of life } \\
\hline PedsQL - Total score & 1.08 & $1.053-1.109$ & $<0.001$ \\
\hline \multicolumn{4}{|c|}{ Final Model } \\
\hline Home-ownership & 2.16 & $1.166-3.984$ & 0.014 \\
\hline Does not go to museums & 2.20 & $1.184-4.074$ & 0.013 \\
\hline Practices some religion & 1.91 & $1.021-3.551$ & 0.043 \\
\hline PedsQL - Total Score & 1.08 & $1.053-1.109$ & $<0.001$ \\
\hline
\end{tabular}

Reference categories: female; lives with another family member or friend; rented housing; does not have health insurance; attends the museum; does not practice a religion; has suffered acts of violence; bad self-perception of health

* Model adjusted by the housing variable (block 1)

** Model adjusted by the housing variable (block 1); attends museums and practices religion (block 2)

*** Model adjusted by the housing variable (block 1); attends museums and practices religion (block 2); Peds_QL - total score (block 4)

Final model adjustment: Hosmer \& Lemeshow $-p=0.512$

Subtitle: $\mathrm{OR}=$ Odds Ratio $\mathrm{Cl}=$ Confidence interval 


\section{DISCUSSION}

In the present study, almost all adolescents classified health as important or very important and more than $80.0 \%$ defined their health status as good or excellent. However, nearly one-third reported to have a health problem. These data demonstrate that, as shown in previous studies ${ }^{16,17}$, self-perception does not necessarily depend on the actual state of health. The literature also shows that the adolescent can interpret "good health" simply as being physically well ${ }^{18}$. Thus, the definition of health for adolescents does not necessarily include their perceptions of general well-being or a broader health-disease process.

The data obtained in relation to good health selfperception differ from other contexts that revealed less robust indexes, varying from $71,0 \%$ a $87,9 \%^{18-21}$. The highest rates of negative self-perceived health were observed in Pakistani studies ${ }^{19}$ and Brazilian studies ${ }^{22}$. The Pakistani study included 414 adolescents aged 14 to 17 years and the prevalence of poor self-rated health was $29.0 \%$. Results emerging from a Brazilian study ${ }^{22}$ of a case-control study with 871 participants revealed negative self-perception of health in $29.4 \%$ of adolescents with reports of physical harm or injuries, as well as $25.5 \%$ in the group not presenting this fact.

Studies conducted with adolescents who are not exposed to situations of social vulnerability or disease, tend to have higher positive self-perceived health outcomes ${ }^{18-23}$. A survey of 1,027 adolescents between the ages of 16 and 18 years attending the first two years of vocational secondary education and belonging to different academic programs in three public high schools in a city in northern Sweden revealed a prevalence of $83.6 \%$ good self-perception of health ${ }^{18}$. These results are similar to a Norwegian study with 2,800 adolescents aged 16 to 20 years, of which $88.0 \%$ rated their health as "good" or "very good"20. A Brazilian study of 820 adolescents aged 10 to 19 years revealed that $12.1 \%$ of the interviewees had regular / bad self-perception of health ${ }^{21}$. Data coming from another Brazilian study revealed $83.3 \%$ with positive self-perception of health in a sample of 501 young adults, 20 to 24 years old, attending regular high school or education for youth and adults (EJA) in public schools ${ }^{23}$.

Analyzing the association between the self-reported health status in adolescents and social determinants, the multivariate analysis of the data indicated that living in one's own home, practicing some religion, not attending museums and referring to a better quality of life increased the chances of having good selfperception of health.

Regarding cultural aspects, although the data indicated association with significance only for religious practice and attendance at museums, a Norwegian study of 8,085 adolescents aged 13 to 19 indicated that participation in other cultural activities may be positively associated with self-perception of health, satisfaction with life and self-esteem in adolescents ${ }^{24}$. It is worth considering that although there is little research dedicated to understand the cultural aspects in adolescent health, it is necessary to expand this analysis, since it may constitute an important axis in the discussion of opportunities and self-concept in this life cycle. Regarding the religious aspects, a study conducted in southern Brazil indicated an absence of statistically significant association between religious practice and self-perception of health ${ }^{21}$. However, there is a difference with the data presented here because the research was related to not practicing religion compared to the denomination of the religion practiced. In the case of the present study, it was investigated exclusively if the adolescents practiced or not a religion.

The present research also revealed that reporting a better quality of life increased the chances of having positive self-perception of health. Studies related to health-related quality of life in adolescents reveal that this aspect has a strong influence on the context in which the subject lives. A study of 1,357 adolescents between the ages of 12 and 17 years in three Latin American countries (Argentina, Brazil and Chile) revealed the influence of sociocultural factors in each country on the subjective evaluation of self-health and well being ${ }^{25}$. In the present study, an increase in one point in the total quality of life score increased by almost $10.0 \%$ the chance of the adolescent to have positive self-perception of health. In this way, the adolescents who positively evaluate other dimensions of life have a better chance of positively evaluating health.

The literature points out that adolescents with lower economic status and educational level not adequate to the age group report worse self-perceived health ${ }^{21}$ but those findings were not corroborated by the results presented here. It is necessary to consider, however, that the sample of the present research shows relative homogeneity related to the economic and schooling situation, since all the individuals come from public schools and they present a similar economic classification, falling mainly in categories $B$ and $C$ of that classification. 
Although the present study considered only the "with whom the adolescent lives" question in relation to the family, other family aspects and their relation with the self-perception of health have already been investigated. It is worth noting a survey of 3,427 high school students in Croatia who indicated that good self-perception of health outcomes was significantly associated with family, neighborhood and school social capital, i.e. how much the adolescents feel supported in these contexts ${ }^{26}$. A Brazilian study ${ }^{27}$ indicated that family social support strongly predicts self-perceived health throughout adolescence, indicating the importance of the family during this stage of development. Thus, it is necessary to consider such variables in future research.

In the present study, no relationship with statistical significance was found between the context of violence and self-perception of health. It is possible that research on this subject was not sufficiently explored with only three questions and that a more in-depth approach may point to different results. It should be considered that the literature ${ }^{21}$ points out differences in the subjective health assessment of adolescents who suffered acts of violence when compared to those who did not, as well as a higher index of self-perceived negative health that was demonstrated in the first group.

The present study shows important associations regarding the self-perception of health of adolescents attending high school in public schools, especially when using probabilistic samples and without associated pathologies; however some limitations should be considered. Although the sample is probabilistic and the study was carried out in sixteen public schools and in the different geographic areas of the municipality, it does not necessarily reflect the characteristics of the high school students as a whole, since privately funded schools were not included. In addition, the selection of schools from only one major city constrains any reference to the perceptions of adolescents in rural areas.

\section{CONCLUSION}

In the present study, the majority of the adolescents classified health as important or very important, and three quarters of them defined their health status as good or excellent. In addition, considering the hierarchical multiple logistic regression model, the fact that the participants live in their own homes, practice some religion and have a better quality of life, increased the chances of having a positive self-perception of health.
The findings of this research point to the importance of quality of life in self-perceived health in adolescents. In addition, aspects related to housing conditions and religious practice should be considered in the study of the subjective analysis of the health condition in the life cycle of adolescence. However, in order to obtain more robust data, it is still necessary to compare the selfperception of health of adolescents in different contexts and cultural, family and school situations.

\section{REFERENCES}

1. Noronha MI, Rodrigues MA. Saúde e bem-estar de crianças em idade escolar. Esc Anna Nery. 2011;15(2):395-401.

2. Sousa TF, Silva KS, Garcia LMT, Del Duca GF, Oliveira ESA, Nahas MV. Autoavaliação de saúde e fatores associados em adolescentes do Estado de Santa Catarina, Brasil. Rev Paul Pediatr. 2010;28(4):333-9.

3. Soares AHR, Martins AJ, Lopes MCB, Britto JAA, Oliveira $C Q$, Moreira MCN. Qualidade de vida de crianças e adolescentes: uma revisão bibliográfica. Ciênc Saúde Coletiva. 2011;16(7):3197-206.

4. Felden EPG, Caumann GS, Sacomori C, Daronco LSE, Cardoso FL, Pelegrini A. Sociodemographic factors and body image among high school students. Ciênc Saúde Coletiva. 2015;20(11):3329-37.

5. Silveira MF, Freire RS, Nepomuceno MO, Martins AMEBL, Marcopito LF. Tooth decay and associated factors among adolescents in the north of the State of Minas Gerais, Brazil: a hierarchical analysis. Ciênc Saúde Coletiva. 2015;20(11):3351-64.

6. Videra-García A, Reigal-Garrido R. Autoconcepto físico, percepción de salud y satisfacción vital en una muestra de adolescentes. Anal Psicol. 2013;29(1):141-7.

7. Pietiläinen $\mathrm{O}$, Laaksonen $\mathrm{M}$, Rahkonen $\mathrm{O}$, Lahelma E. Self-rated health as a predictor of disability retirement - the contribution of ill-health and working conditions. PLoS ONE. 2011;6(9):e25004-11.

8. Louvison MCP, Lebrão ML, Duarte YAO, Santos JLF, Malik AM, Almeida ES. Inequalities in access to health care services and utilization for the elderly in São Paulo, Brazil. Rev Saúde Pública. 2008;42(4):733-40.

9. Miilunpalo S, Vuori I, Oja P, Pasanen M, Urponen $H$. Self-rated health status as a health measure: the predictive value of self-reported health status on the use of physician services and on mortality 
in the working-age population. J Clin Epidemiol. 1997;50(5):517-28.

10. Lucumí DI, Grogan-Kaylor A, Espinosa-García G. Asociación de la posición socioeconómica y la percepción del ambiente con la autopercepción del estado de salud en mujeres de Bogotá, Colombia. Rev Panam Salud Publica. 2013;34(1):14-20.

11. Etxaniz IE. Desarrollo del autoconcepto durante la adolescencia y principio de la juventud. Revista de psicología general y aplicada. 2005;58(2):265-77.

12. Esnaola I, Goñi A, Madariaga JM. El autoconcepto: perspectivas de investigación. Rev psicodidáct. 2008;13(1):179-94.

13. ABEP: Associação Brasileira de Empresas de Pesquisa [homepage on the Internet]. Critério de Classificação Econômica Brasil [cited 2017 Jun 9]. Available from: http//www.abep.org/criterio-brasil.

14. Klatchoian DA, Len CA, Terreri MTRA, Silva M, Itamoto C, Ciconelli RM et al. Quality of life of children and adolescents from São Paulo: reliability and validity of the Brazilian version of the Pediatric Quality of Life Inventory TM version 4.0 Generic Core Scales. J Pediatr. 2008;84(4):308-15.

15. Lima L, Guerra MP, Lemos MS. Adaptação da escala genérica do inventário Pediátrico de Qualidade de Vida - Pediatric Quality of Life Inventory 4.0 PedsQL, a uma população portuguesa. Rev Port Saúde Pública. 2009;8(1):83-95.

16. McCrindle BW, Zak V, Pemberton VL, Lambert LM, Vetter VL, Lai WW et al. Functional health status in children and adolescents after Fontan: comparison of generic and disease-specific assessments. Cardiol Young. 2014;24(3):469-77.

17. Homlong L, Rosvold EO, Bruusgaard D, Lien L, Sagatun $\AA$, Haavet OR. A prospective population-based study of health complaints in adolescence and use of social welfare benefits in young adulthood. Scand J Public Health. 2015;43(6):629-37.

18. Wiklund $M$, Malmgren-Olsson EB, Öhman A, Bergstrom E, Fjellman-Wiklund A. Subjective health complaints in older adolescents are related to perceived stress, anxiety and gender - a cross-sectional school study in Northern Sweden. BMC Public Health. 2012;12(1):993-1006.

19. Afridi AAK, Motwani K, Khawaja S, Khoja AA, Fatmi Z, Azam I et al. Self-perceived health among school going adolescents in Pakistan: influence of individual, parental and life style factors? Glob J Health Sci. 2013;5(4):71-8.

20. Breidablik HJ, Meland E, Lydersen S. Self-rated health in adolescence: a multifactorial composite. Scand J Public Health. 2008;36(1):12-20.

21. Reichert FF, Loch MR, Capilheira MF. Autopercepção de saúde em adolescentes, adultos e idosos. Ciênc Saúde Coletiva. 2012;17(12):3353-62.

22. Pattussi MP, Lalloo R, Bassani DG, Olinto MT. The role of psychosocial, behavioural and emotional factors on self-reported major injuries in Brazilian adolescents: a case-control study. Injury. 2008;39(5):561-9.

23. Moreira TMM, Santiago JCS, Alencar GP. Self-perceived health and clinical characteristics in young adult students from the brazilian northeast. Rev Esc Enferm USP. 2014;48(5):794-803.

24. Hansen E, Sund E, Knudtsen MS, Krokstad $S$, Holmen TL. Cultural activity participation and associations with self-perceived health, life-satisfaction and mental health: the Young HUNT Study, Norway. BMC Public Health. 2015;15(1):544-52.

25. Guedes DP, Astudillo HAV, Morales JMM, del Campo Vecino J, Pires Júnior R. Calidad de vida relacionada con la salud de adolescentes latinoamericanos. Rev Panam Salud Publica. 2014;35(1):46-52.

26. Novak D, Suzuki E, Kawachi I. Are family, neighbourhood and school social capital associated with higher self-rated health among Croatian high school students? A population-based study. BMJ Open. 2015;5(1):e007184-93.

27. Meireles AL, Xavier CC, Andrade ACS, Proietti FA, Caiaffa WT. Self-rated health among urban adolescents: the roles of age, gender, and their associated factors. PLoS ONE. 2015;10(7):e0132254-68. 